\title{
Australian students going to the Pacific Islands: International social work placements and learning across Oceania
}

Jioji Ravulo, University of Wollongong, Australia

\begin{abstract}
INTRODUCTION: This paper explores various issues pertinent to international social work practice, including its definition, how Western epistemologies affect international placements, barriers to effective placements and student motivations for undertaking practicum away from home.

METHOD: Reviewed literature will be coupled with Australian student-participants' evaluations of their experience in completing social work placements in Fiji and Samoa.
\end{abstract}

FINDINGS: A new model of approaching Pacific social work across Oceania emerges from the study. Entitled Tanoa Ni Veiqaravi (Serving Bowl of Serving Others), this culturally nuanced framework integrates both Western and Pacific social work perspectives to support professional practice, policy development and research across the region.

CONCLUSIONS: Recommendations for the improvement of international field practice are offered.

Keywords: International Social Work; Field Education; Pacific Islanders

AOTEAROA NEW ZEALAND SOCIAL WORK 30(4), 56-69.

CORRESPONDENCE TO: Jioji Ravulo jioji@uow.edu.au
The desire for tertiary institutions to provide global learning opportunities for students is a growing trend across Australian universities. The ability to provide an international experience whilst completing field education placement hours' requirements is attractive to students and can provide universities with opportunities for teaching and research endeavours. However, how do we ensure that students from the Global North are prepared to participate in such learning and are aware of their biases? The issues may, in turn, be perpetuated by westernised perspectives within the social work profession itself. This article explores tensions and possibilities for collaboration between local knowledges and social work field education, providing a new approach to further assist in bridging this divide.

\section{LITERATURE REVIEW}

\section{Defining international social work}

The effects of colonisation and globalisation have deeply impacted upon social work as a professional field. These realities are now more defined than ever, as there is an increasing focus on the validity and, as perceived by some, the necessity of internationalising social work as a profession 
to combat social inequalities that have emerged in the wake of globalisation. There is also an ongoing need to recognise the importance of indigenous peoples around the world and their ontologies and epistemologies in social work practice.

In order to evaluate the features and effectiveness of international social work programmes, it is pertinent to define what international social work means, as there is a lack of clarity regarding its definition and its implications. Nuttman-Shwartz and Berger (2012) state that international social workers are those who possess "professional practice that crosses national boundaries" (p. 227). They believe it should be redefined as: "[a] professional discipline that promotes transnational knowledge studies and experiences to foster equality and justice as vehicles of international understanding, collaboration and collective human development" (p. 228).

International social workers, then, are those who attempt to reduce the impacts of globalisation on social problems, and seek to "prevent the erosion of human rights" (Nuttman-Shwartz \& Berger, 2012, p. 237), to protect "excluded and neglected populations, and provide support during crises in developing countries" (p. 237). However, international social work is not cross-cultural social work. The former focuses on "comparative social development, social problems, social welfare and social policy" (p. 228); the latter focuses on "cultural diversity, inter-cultural communication and cross-cultural understanding" (p. 228). Within this context, cultural competence aids understanding and is the "crucial link between immersion in the new cultural context, practice encounters and theory" (Parker, Ashencaen Crabtree, Azman, Carlo, \& Cutler, 2015, p. 42). There is recognition of the need for praxis to be carried out, not only through "the hegemonic constructions mandated by the Global North" (p. 43), but that which seeks to apprehend and understand "indigenous and authenticised bodies of knowledge" that can impact upon practice (p. 43). Inherent in this approach is an understanding that "the unquestioned 'superior positioning' of western paradigms" (p. 43) is brought into scrutiny, as these concepts promote Western hegemony.

\section{Western imperialism and international placements}

The domination of Western values and practices within social work cannot be ignored, and has been described as "professional imperialism" (NuttmanShwartz \& Berger, 2012, p. 229) that duplicates its models all over the world, treating the Western practitioner as the "expert" even when in non-Western countries, "while ignoring power differences between them" (p. 229). Yeom and Bae (2010) highlight how Western practices can be imposed upon Korean social work practice, and argue that there ought to be "a constructive analysis of westernized practices and indigenous needs...[rather than] international exchanges [which] are suffused with the legacies of colonialism and imperialism" (p. 311). The idea of Western hegemony is "inherent in western pedagogy, practice, education, and attempts at globalization" (p. 315) and social workers "have an ethical responsibility to question international exchanges in this light" (p. 315). This responsibility demands that they address issues such as the "tripartite dilemma [of] indigenization, universalism and imperialism" (p. 315) that faces international social work. This responsibility extends to supervisors, who may unwittingly impose Westernised methods of practice at the expense of indigenous models (Mathiesen \& Lager, 2007; Cleak, Anand, \& Das, 2014).

\section{Western and non-Western issues and practice}

Some Western concepts, such as individualism, objectivity, professional distance and self-determination are notably "incompatible with other, more collectivistic cultures that value interdependence" 
(Nuttman-Shwartz \& Berger, 2012, p. 230). For Western practitioners in non-Western contexts, there needs to be an integration of their cultural values with those of the host (p. 230). Social work in some contexts seeks to "assimilate western theories" within their own practice, which can be counterproductive to creating indigenized social services, which "support a two-way exchange of knowledge" between two cultures (p. 231). This neo-imperialism, should it persist, promotes "misconceptions and cultural stereotypes" and reproduces "social injustice, inequities in international involvement and oppressive relationships" (p. 231). Yeom and Bae (2010) believe that students from non-Western cultures are poised to benefit from these programmes in that they are able to ascertain the best practices from the West, and reject those practices that are least helpful within their cultural contexts (p. 324).

\section{Benefits of international social work placements}

International field practicums are understood to be "a key way to foster cultural competency and acquaint students with the ways in which globalization affects social welfare" (Yeom \& Bae, 2010, p. 312), and can serve to make social workers "internationally ready" (Nuttman-Shwartz \& Berger, 2012, p. 227). Such programmes have the potential to shift institutions' approaches to field placement, encouraging "the development of agencies for the practicum which previously had little understanding of the scope and role of social work" (Yeom \& Bae, 2010, p. 313). Further, forming the networks for these placements serves to not only bolster an "integration of knowledge and values", but "can act as a force for organisational change and a catalyst for social development" (pp. 313-314).

International placements have the potential to "redress inequalities in a global context" (Bell \& Anscombe, 2012, p.1033). They emphasise the need for social work in the 21st century to respond to challenges in the "economic, political and cultural relationships between people across the world" (p. 1033) on local and global scales in all forms of its practice. The core values of social work, empowerment, social justice and human rights, highlight the profession's emancipatory ethos, and can be enacted through internationalising the profession.

\section{Motivations for doing international placement}

Having conducted many international social work practicums in both Canada and Lebanon, Wehbi (2009) emphasises the need for practicums that actively understand students' motivations so as to negate "reproducing inequitable North/ South power relations" (p. 49). Essentialising the characteristics and needs of the different people groups served through such placements inhibits social workers' abilities to assist them, and does not aid in respectful and meaningful engagement with individuals. Students must come to realise that "ethnic heterogeneity is the 'norm, not the exception"' (p. 48). Wehbi suggests that, by conducting thorough preparatory programmes which detail relations between the country of residence and country of placement, there would be a more contextualised awareness of the relationship between the two countries which would make such placements more effective. These programmes could also include foci on "resistance, alliance-building and personal agency" (p. 55), so as to "reverse North/South power relations" (p. 54), and also prepare students cognitively and emotionally regarding power relations in society, assessing situations from an organisational perspective, understanding the potential risks of placements, the historical roots and current realities of the host country and how these are impacted by global economics, political pressures and colonialism, the relationship between the home and host countries, and the level of contribution that they can expect to make 
within these social work settings (NuttmanShwartz \& Berger, 2012).

\section{Perceptions and skills developed by social workers}

Several attitudes and perceptions emerged from the literature as a result of students' experiences on placement. Some considered it helpful to be modest, and maintain a "listening and respectful attitude, letting the host take the lead, and contributing only as the host invites" (Magnus, 2009, p. 376), all the while seeking to learn and gain professional competence, especially through mistakes. Students often became more informed in the political and social realities of these communities which, in turn, inspired advocacy in their home countries (p. 376). These experiences also taught students the importance of being aware of a diversity of values which often comes from understanding oneself and one's cultural bents better (p. 376). Several authors highlighted the importance of students keeping continuous note of their placement experiences, so as to encourage their personal and professional development in the field (Crabtree et al., 2015; Marlowe, Appleton, Chinnery, \& Van Stratum, 2014; Nuttman-Shwartz \& Berger, 2012; Magnus, 2009; Wong \& Pearson, 2007). These include students naively practising without being critical of their own cultural imposition (Crabtree et al., 2015), and students developing the ability to suspend their own judgments and being completely present with the client (Marlowe et al., 2014).

\section{Placement models and considerations for good practice}

Several models for international placements have been identified throughout the literature. One of the most drawn upon is that of Pettys, Panos, Cox, and Oosthuysen (2005), who describes four models:

1. Independent/one-time placements in a specific geographical region;
2. Neighbouring country model, where students were residents or citizens;

3. On-site model where adjunct faculty member in host country could stay as on-site field supervisor;

4. Exchange/reciprocal model, in which the home university sent faculty members to the placement site at their own expense. (pp. 282-287)

Apart from the models themselves, Mathiesen and Lager (2007) identify specific areas that these placements ought to fulfill: establishment of a feedback loop with potential participants; to gain an overview of the other country; to provide orientation at micro, mezzo and macro levels; to identify gains, consider costs; clarify expectations, and establish roles for the student, field liaison, and field supervisor. This model emphasises long-term relationships and "commitment to reciprocity at all stages" (p. 280).

There is an expressed need and recognition for international social work at this level, but it appears that many institutions are not truly moving in a direction that will foster such relationships (Mathiesen \& Lager, 2007). A lack of understanding and clear communication between all parties involved at every stage of such programmes, particularly for the students and supervisors, can occur, and consequently, cultural factors are used as the scapegoat for their breakdown (p. 280). Evaluations should, therefore, be mutual, and not only coming from the student(s) undertaking practicum.

Selection for such international placements ought to happen on the basis of one's ability to deal with stressful and insecure situations, interpersonal communication style and the "ability to interact effectively with people of diverse cultural backgrounds" (NuttmanShwartz \& Berger, 2012, p. 236). This does not simply mean having cultural, ethnic and racial sensitivity but, rather, "high levels 
of maturity, flexibility, adaptability and perceptiveness to cultural norms [that] are necessary prerequisites for students to live and work abroad" (Mathiesen \& Lager, 2007, p. 286). Bilingual students are highlighted as having an advantage in many host countries, though such enterprises can stimulate a desire to learn languages.

\section{University of Western Sydney student experience}

The next section details the experiences of University of Western Sydney social work students who took part in that university's placement programme for three months, completing 500 hours of a required 1000 hours to be eligible for accreditation as an Australian social worker through the Australian Association of Social Workers (AASW). The placements discussed here took place between 2013 and 2015. Most students completed their placements in and around Suva, Fiji; with one student completing in Samoa. A total of eight students were interviewed, and their perspectives shed light on pertinent issues involving international student placement in the Pacific, and how these impacted upon their experiences as developing social work professionals. Importantly, one ought not to speak of the Pacific Region as a collective whole; it is made up of many different languages, cultures, and ontological and epistemological understandings, and obviously heterogeneous people groups, even within one nation. Therefore, the countries of Fiji and Samoa, which were countries of placement for students, are treated separately throughout this article.

\section{METHODOLOGY AND METHOD}

\section{Methodology}

Indigenous methodologies play an important role in creating a broader understanding and approach to knowledge - not just within a neo-colonial context, but also within a larger scope to decolonize the way in which we construct and deconstruct knowledge in teaching and learning. To uphold a genuine commitment to such perspectives, this research acknowledges the "transformative power of indigenous knowledge, the ways that such knowledge can be used to foster empowerment and justice in a variety of cultural contexts" (Kincheloe \& Steinberg, \& Shirley, 2008, p. 132). Consequently, students within a learning context can experience multilogicality (p. 132) - where one starts to see the world as complex, rather than linear, upholding imperial notions of Western epistemological and ontological truths. As students recruited into the the University of Western Sydney initiative came from varying socio-ethnic, socio-cultural, and socio-economic backgrounds, this research methodology provides further opportunities to validate the individual experience within the larger group. That is, as people actively contribute to their learning space enabled to share their perspective, this creates a greater platform for diversity to be explored, as "in this sense, different frames of reference produce multiple interpretations and multiple realities" (p. 138). Underpinning this construct is the much-valued narrative approach, where participants contribute their perspective in a meaningful way. Additionally, in upholding the approach of challenging the researcher as the gatekeeper of knowledge, the findings in this article have been presented to reflect the key themes by directly utilising key words and statements participants have provided; rather than the researcher placing their own interpretation on the data given. In turn, this deters a traditional power imbalance that may occur between a researcher and participant.

\section{Method}

In the spirit of talanoa, a Pacific concept of sharing through articulating your collective thoughts and feelings within a group, widely evident across indigenous cultures throughout Oceania (Vaioleti, 2006), all 12 students who had previously participated in the University of Western Sydney programme were invited 
to gather to share their experiences. Nine questions were asked as part of a semistructured group interview, divided into two sections - "Pacific social work questions" and "Post placement questions." Students were given the opportunity to contribute as much as they felt comfortable, with responses recorded via hand-written notes and an audio-recording device. As not all students were able to attend the group interview, with five in attendance, interviews with the additional three students were conducted individually via telephone; still promoting scope for students to contribute communally through the data-collection phase of this study. Overall, this notion of inclusion fostered a shared approach to understanding the experience of social work education around international student placements. As mentioned earlier, key themes were developed directly from the narratives participants shared, rather than assumed by the researcher; ensuring indigenous, and non-indigenous perspectives are understood and valued in their immediate and present context.

\section{Ethics}

Ethics was granted for this project by the Human Research Ethics Committee at the University of Western Sydney. All participants completed written consent forms or agreed verbally to provide consent for their views to be shared, which was electronically recorded.

\section{KEY FINDINGS}

\section{Perceptions of social work in the Pacific}

One of the most significant impacts upon the students' experience in the Pacific was the way that social work is perceived there. There were notable differences between Fijian and Samoan perspectives of what a social worker was. In Fiji, a social worker is understood to be someone "probably [like] a counsellor, along that line," or anyone who helps someone else - "it's quite fluid, in the sense that everyone in the organisation can be a social worker" (a participant). One student expressed it in this way:

A social worker is defined as somebody who helps someone in the Pacific Islands. And that could be somebody retired from a finance background, but now retired in a CEO's position - being in charge of the whole service, and not actually having a social work system in how they're thinking.

This very general definition of a social worker means that people from any professional background with a desire to help other people are considered to be social workers, even without any specific training in the field. One student remarked that "you didn't have to do much to identify with [being a social worker]...it wasn't given a huge value [as] it is here in Australia".

In Samoa, the profession is "not really... recognised", and "there are other social workers, but they're in completely different fields. So as a profession it's not very well known." The student on placement in Samoa reported that, apart from herself, her supervisor was the only other known and professionally trained social worker.

Various reasons for such an understanding of social work in the Pacific were put forward by participants, including the general perception of social work as "women's work," and something which is done "out of your love, not out of a particular need or for the pay." As a result, participants noted that social work, while needed, is "given a lesser value" as a profession. Coupled with the very strong presence of volunteerism in both Fiji and Samoa, one may perceive social work as not a needed area of professional expertise within the region. Some students even stated that, when describing their career to some on placement, "they all kind of laughed off the profession almost." The understanding of the profession, being in a nascent stage in the Pacific, requires 
ongoing presence and must prove its worth if it is to be validated in a cultural context that has for centuries depended on (nonWestern) practices and traditions to sustain and support their peoples. However, the need to professionalise such activities may also fall in line with ongoing social stratification occurring across the Pacific due to globalising influences, and the need to compete with capitalistic expectation and realities. As a result, marginality is becoming more evident, and the need to create a shared approach between Western and Pacific perspectives is enhanced.

\section{Experiences on placement: challenges and honing skills}

In light of these perceptions of social work in Fiji and Samoa, the profession in these countries does not receive the same levels of support and funding from governments as in most Western countries. Frequently students highlighted difficulties in accessing appropriate facilities, such as interview rooms, pens, and basic necessities needed to complete practicum tasks, including obtaining sensitive information from clients. Time and again, a lack of funding was stated to impede the ability of social workers in these two nations from serving their populations in a more professional manner. At the same time, the importance of certain practices has not yet been captured and appropriated within Fiji and Samoa, such as the need to develop detailed case note writing and referral systems that could assist clients if the organisation itself could not provide further assistance. Participants did a lot "from scratch" as a result, with one student even putting together "a yellow pages [directory] of services" to assist in referring clients to the most appropriate organisations to meet their needs. One student powerfully encapsulated this reality and the effect it has on the social work profession:

While in Fiji, it occurred to me that there's more of a reliance on an individual social worker and their skills, than there is on the service in itself. Because it really came down to how well connected and how creative that social worker could be in accessing support for their client, and how skilled they were to [do that]. As opposed to the service having a huge amount of funding and being able to just, you know, access everything....

One of the major points highlighted by the participants was the lack of supervision, which has been considered one of the most important aspects of sustaining professional social work practice. As social workers in Fiji can be drawn from a range of backgrounds and not specifically trained in social work, this can create a frustrating and potentially unsafe situation for students doing placements:

If you're stuck in an ethical situation, who are you going to go to? Your supervisor's someone from finance or someone from legal, and they're not able to provide that support that you need. In terms of self-care, in terms of situations that involve risk.

As a result of some of the students' challenges, the importance of indirect social work was repeatedly mentioned, which fostered a sense of sustainability for the organisations they worked in. One student conveyed this concept:

Everyone views social work as direct placement...or as direct exposure... you could see how indirect social work provides sustainability for organisations, and that was probably the biggest lesson I learned about social work and the need to build, you know, connections with organisations, write policies, do evidencebased research...I mean, that's how an organisation is going to continue doing [its work].

The importance of indirect social work was not considered as significant prior to these placements. Despite the apparent lack of resources within Fiji and Samoa, University 
of Western Sydney participants were able to hone their aptitudes in these areas, and emerged from the placements with increased confidence and a sense of validation:

When I was in Samoa, I felt like a real social worker. You end up feeling really validated by the end of it.

Students felt that their skills were needed and regarded as such within the organisations that they worked for, even though on a national scale social work was not very well understood as a profession. While some felt apprehensive in taking part in the programme initially, their confidence grew noticeably as a result of participating. At the same time, their ability to further understand cultural perspectives and practices as part of their learning was evident; informing their learning outcomes and the way in which University of Western Sydney was implementing the respective placement model.

Other lessons from the experience were students' ability to develop patience, especially regarding different perceptions and promptness with time, finding "my own way to learn about things," the importance of boundaries and being aware of the self and the importance of self-reflection in social work practice.

\section{Experiences after placement: considerations for next time}

When asked to consider what they would change about the Western Sydney programme, most participants wanted a more detailed explanation and orientation regarding living in their country of placement for three months. Students maintained that there are often romantic, and quite false notions surrounding the Pacific Islands. Realistic accounts of former University of Western Sydney student experiences are important aspects of orientation programmes that can set realistic expectations for students seeking to complete placement overseas. Other issues included the need for groups completing placements together to have social gatherings before departing for the Pacific, to ensure that personalities could be mutually encountered and any potential clashes be apprehended prior to commencement. One student suggested that there be more exploration of Pacific social work models prior to departure, alongside more Pacific students taking part in the programme, as they have cultural insider knowledge that is often very helpful in experiencing different aspects of the placement countries. Interestingly, for one student who was from the placement country, there have been noticeable developments in her heritage culture which she, too, needed to comprehend:

I learnt that I needed to understand the culture - I remember the culture...when my parents lived there and what they taught me, but culture as we have learnt is evolving and it has changed. I found that some cultures were replaced to fit in with the demands of the Western culture, and this contributed to the positive and negative issues of social work due to evidence based practice.

Some students highlighted the need to know more about services within the placement countries and even within their specific organisations prior to departure. One student emphasised the importance of being made aware of cultural practices, as it is a sign of respect already knowing all of this, instead of them having to brief you when you get there. This also highlights the need to parallel social work concepts, perspectives and skills within a Pacific context. Such notions of deconstructing previously learnt social work theories to then reconstruct and include Pacific knowledges in a meaningful manner might be part of this approach.

Better international field placements are therefore dependent upon more comprehensive orientation programmes that prepare students for the cultural realities of 
living in their placement country, as well as information pertaining to "dos and don'ts" that translate to cultural understandings of the place(s) being visited. As a result of their experiences, participants from this project developed further guidelines and other support documentation for future students wanting do a placement in the Pacific.

\section{Experiences after placement: impartations from international exchange}

Despite some of the difficulties encountered in placements in Fiji and Samoa, there was a resounding sense that students had walked away deeply challenged relative to their own perceptions of social work, the development of their skills as practitioners, and gratitude for the experience of being able to partake of an entirely different cultural setting and to be of assistance to those in need through their organisations' work:

Having the opportunity to be immersed in a culture for that amount of time is such a good way to build on...your cultural competencies, and really being able to understand what the culture is about.

One student emphasised the importance of her placement, stating that Fijian culture is "something that we all have to learn something from." She also highlighted the dilemma she experienced when she initially came to Fiji; her initial reaction was one of "Oh my God, this is all wrong, these people are wrong." After time passed, however, she thought, "Oh my God, I'm so wrong! I'm a completely wrong human being!" This then plateaued to an understanding that "nobody's wrong." This process of acclimatisation to a new culture has left a definite imprint upon the social work practice and worldview of this student.

This same participant expressed one of the most profound statements brought out from these interviews in her understanding of how she had grown as a burgeoning social worker. I quote her at length here, as her words powerfully capture the potential potency of such placements:

I learnt that I'm definitely not the expert in anything, and I think that's a really good thing to learn as a social worker. That social work isn't about being a professional and an expert. It's about...I went there knowing nothing....and learning as I went along, and I just think that's how a social worker should be in this world. I think a social worker should go into a position believing that they know nothing and learning. Learning with the client. Never going there as a professional thinking they know better. Never never never never never.

We might know how to get the funding, or we might know how to contact other agencies, and we might have a better skill in typing on a computer than other people. But we certainly under any circumstances don't know anything about what these peoples' lives are like and what it is that they need. They know that.

Although this student initially faced significant culture shock when she arrived in Fiji, her placement taught her to assume a posture of humility and learning rather than as an expert with Western models and ideologies. This issue remains a site of tension, even within the perspectives shared earlier. Several models of Pacific social work have been written about at length (Faleolo, 2009, 2013; Lauta-Mulitalo, 1998; Tamasese, 2002; Tamasese, Peteru, Waldegrave, \& Busch, 2005; Tuafuti, 2011); if orientation programmes covered some of these models, and implementing them formed part of the assessment for students while in the Pacific, this would serve to greatly bolster their own sense of crosscultural awareness, potentially provide more relevant frameworks for practice when in the Pacific, and orient these students in epistemologies and ontologies that are 
more relevant to Pacific peoples. Utilising these practice models would also redress colonialist ideologies that can be present when social workers from the Global North (including Australia) come to the islands with their Western educational practices and values, which are often assumed to be better simply because they are more developed. This is not necessarily the case, and if Pacific models are not understood by students who take part in such placements, the professional imperialism mentioned by Nuttman-Shwartz and Berger (2012) will continue to be present.

Despite these realities, the experience of completing a placement in the Pacific was seen as deeply rewarding and enriching for all involved. When one student was asked what they would say to another student contemplating a Pacific placement through the University of Western Sydney programme, she responded in the following way:

Definitely do it...You'll never do anything more rewarding, more educational for your learning, more, I would even say soul-searching than what you'll do in this.

\section{IMPLICATIONS: A NEW MODEL}

\section{Tanoa Ni Veiqaravi ("Tah-noah Nee Ve-in-ga-ravi”) - Serving Bowl of Serving Others}

In the desire to take into consideration the learning gained in preparing and sending social work students to undertake a placement in the Pacific, a new model has been developed to support the teaching and learning of both contemporary approaches in social work, and Pacific values and ideals. Previous models developed to work with Pacific communities have incorporated traditional Pacific epistemologies and perspectives as a universal framework; with the view that such perspectives underpin, and apply in, differing contexts based on the practice approach or discipline (Ravulo, 2016). For example, the Fonofale model postulated by Pulotu-Endemann (PulotuEndemann, 2001) was initially developed to broadly support public health initiatives for Pacific communities. The new model being outlined in this article has been developed to assist students and practitioners to further appreciate the synergy between Western ideologies in social work, and the role Pacific epistemologies play in professionalising social work approaches with Pacific people, both in the diaspora across Australia and Aotearoa New Zealand, and communities living across the Pacific Islands. The model is called Tanoa $\mathrm{Ni}$ Veiqaravi, a Fijian phrase translated in English as the "Serving Bowl of Serving Others." As social work has been traditionally viewed in the context of human services, the notion of serving others is ingrained in Pacific discourses, further nuanced by the notion of solesolevaki, the idea that an individual's duty is to innately support both self and others in everything they do and undertake concerning the family and community.

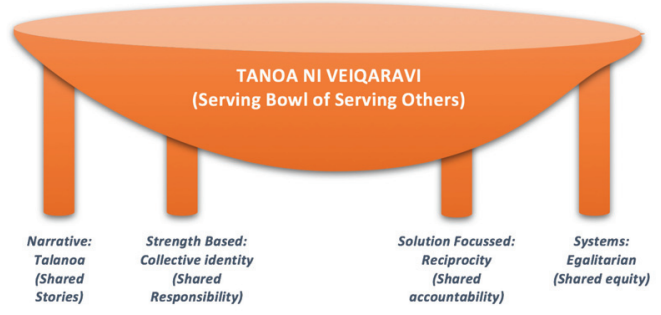

Figure 1. Tanoa Ni Veiqaravi ("Tah-noah Nee Ve-inga-ravi”) - Serving Bowl of Serving Others

As noted in Figure 1, the model is visualised by a tanoa, a serving bowl traditionally used to serve kava. Kava is a grounded root used culturally by Pacific people in rituals and ceremonies, and is commonly used as a gift symbolising the reaching of an agreement or acceptance of self, and family in community. The tanoa is a symbol of bringing people together (Ravuvu, 1983), where groups will sit around the serving bowl to talanoa; participants express and share individual perspectives in the context of the community and their overall wellbeing (Farrelly \& 
Nabobo-Baba, 2014). In essence, by using the tanoa illustration, I am inferring that social work, or the social work practitioner themselves, is the conduit through which service to others occurs. That is, people are able to come together through the support of social work, to discuss and reflect on areas of celebration, communal concern, and possible strategies to overcome such situations.

Social work as a profession is then underpinned by the four legs or approaches that uphold effective and engaging service with Pacific people: narrative, strength based, solution focussed and systems. Each leg is then nuanced by a cultural perspective, and leads to a shared outcome.

The narrative approach has been utilised in social work to assist individual, groups and communities understand their experience, positioning an insight into in the past, how this has impacted the present, and considerations for the future (Burack-Weiss, Lawrence, \& Mijangos, 2017). The benefits of a narrative approach in this cultural framework is supported by the notion of talanoa; where individuals share their own insights and perspectives on situations and circumstances (Vaka, Brannelly, \& Huntington, 2016). Traditional stories reflecting Pacific ways of thinking, knowing, doing, and becoming also resonate with the concept of talanoa, as people will come to understand their own realities in the context of previous family encounters, or narratives passed through generations to further highlight possible skills and attributes that will assist in overcoming certain adversities. A narrative and/or talanoa approach promotes a shared story, reiterating the importance placed on the individual being inextricably connected and bound to others in the immediate, and extended family; let alone shared stories developed over time through other relationships evident through kinship and regional ties underpinned by a connection to land, space and place.

A strength-based approach has provided scope in social work to acknowledge, and highlight the possibilities beyond an individual circumstance or situation. By reviewing the possible skills, attributes, talents or gifts of a person, one is able to possibly utilise such qualities to work towards the betterment of self and others (Kemp, Marcenko, Lyons, \& Kruzich, 2014). In the context of Pacific communities, being part of a collective identity is part of the strength in itself, where we are stronger as a community by communally contributing to each other's wellbeing and including a sense of purpose and place across society (Mafileo \& Vakalahi, 2016). This notion of shared responsibility provides further awareness to how an individual strives to achieve, as one's own success translates to the success of others. For example, within a family, an individual's identity is underpinned by the reputation and success of others within it, and a family's name holds merit in understanding your social standing across a community. Each individual in the family is then responsible for upholding this positive association to a family's name, further offset by the need to contribute positively to other families in and around your own community. Therefore, the ability to utilise individual and family strengths to support and assist wellbeing, and to forge ahead despite adversity reflects this approach in social work within a Pacific context.

A solution-focussed approach promotes scope for individuals to look towards possibilities, and search to overcome various difficulties. An alternative perspective is provoked through an individual's desire to change, and to be part of the process that may be underpinned by nominating goals, or other achievable outcomes (Payne, 2014a). Within a Pacific perspective, solutions are developed to benefit a wider range of people; not just the individual developing the goal, but others connected through the family unit or local community. A desire then to promote a solution that will also provide a reciprocal benefit to the wellbeing of the community is part of also enhancing a shared accountability to self and others (Mafileo \& Vakalahi, 2016). 
For example, the need to promote positive physical health may be offset by the ability to secure and sustain food crops within a family home. The family's ability to harvest such produce for their own meals, but also for the benefit of others, like neighbours, is also at the forefront of this notion of shared accountability - if one family is able to share their naturally sourced and purchased food with others, then the others will reciprocate by sharing their produce and food items. Furthermore, this notion is adopted in regional, and urban settings, further fostering a level of community and sense of belonging.

A systems theory approach strives to look holistically at an individual, and peruse the various systems one is involved in; ranging from family systems, local community support systems and overarching societal systems that also permeate and pervade (Payne, 2014b). These micro, meso and macro perspectives are also evident across Pacific communities, where everyone plays a role in supporting the functioning of a family, local support groups and regional development (Emerging Pacific Leaders Dialogue Alumni, 2007). Pragmatically, every individual is born into a family that brings a certain role and responsibility in a particular community/village. The ability for one family to carry out their duties promotes scope for others to benefit - this egalitarian context then promotes a purpose for people to contribute accordingly. This shared equity enables people to uphold a system that is underpinned by a desire for being fair and just which, accordingly, impacts on an equal opportunity system in Pacific society. Granted, such tenets may be somewhat aspirational and thinning in the face of capitalism and consumerism; however, the scope to promote a sense of purpose to an individual and their family is still held in high esteem.

By developing a model of this nature, we are striving to support the development of Pacific social work education; where indigenous knowledge and perspectives are meaningfully integrated into teaching and learning practices across Oceania. To support the implementation of practices, policy and research across the region, students, like those from Australia, are reminded of the existing strengths and capabilities of communities in the Pacific Islands. Students are also able to enhance their perspectives whilst re-shifting their own positions of privilege that may hinder working collaboratively with indigenous peoples. The model may also assist in promoting the development of existing social work practices to be more nuanced and rigorous, where the notion of community development is seen as more than economic outputs alone, but also guided by existing forms of cultural and social capital that lead to more fair and sustainable outcomes.

\section{CONCLUSION}

Despite the challenges of working in nations where social work is not yet fully recognised as a profession, and not as valued as it might be in Australia, all students grew in their professional and personal lives as a result of the experience. Their insights have revealed areas of improvement for future placement programmes, such as a need for more detailed understanding of services available in these countries, the ongoing struggle to have social work recognised as a legitimate and valuable profession within the region, and the potential impact of such services for clients and their practitioners. Due to the limited timing and ethics approval of the research project, the ability to directly consult with local stakeholders in Fiji and Samoa who were involved in supporting the placements was affected. Future explorations on the viewpoints of service providers, and clients themselves on the role of social work in the region will further enhance the positionality of the profession. Through the introduction of the Tanoa Ni Veiqaravi model via this research article, we are striving to emphasise and promote Pacific voices and their influence to further promote the inclusion of such perspectives in a more meaningful 
relationship between social work approaches evident across the Global North and South.

It is hoped that the recommendations from this paper to further understand the distinctions of Pacific social work and its ability to interact and guide westernised forms of the profession in the region will inform future ontological positions around arranging and conducting social work placements across Oceania, specifically drawing upon Pacific epistemologies as a part of training students in preparation for such placements. Australia is in a unique position to implement placements funded via government study loans that bridge Western and Pacific knowledges in social work practice. Working collaboratively with our Pacific neighbours and engaging their organisations from a position of humility and learning could potentially transform understandings of the social work profession and create integrated models that are unique, people-centred, and cater to the needs of the diverse region that is the Pacific.

\section{References}

Bell, K., \& Anscombe, A. W. (Bill). (2013). International field experience in social work: Outcomes of a short-term study abroad programme to India. Social Work Education, [online October 2012], 1032-1047. http://doi.org/10.1080/ 02615479.2012 .730143

Burack-Weiss, A., Lawrence, L. S., \& Mijangos, L. B. (2017). Narrative in social work practice: The power and possibility of story. New York, NY: Columbia University Press. https://doi.org/http://dx.doi.org/10.7312/ bura17360

Cleak, H., Anand, J., \& Das, C. (2014). Asking the critical questions: An evaluation of social work students' experiences in an international placement [Advance Access December 2014]. British Journal of Social Work, 1-20. doi:10.1093/bjsw/bcu126

Crabtree, S. A., Parker, J., Azman, A., \& Carlo, D. P. (2015). Typologies of student experiences and constructed meanings of learning in international placements. Asia Pacific Journal of Social Work and Development, 25(1), 42-53. http://doi.org/10.1080/02185385.2014.1003393

Emerging Pacific Leaders Dialogue Alumni. (2007). Through Pacific eyes: A collection of stories, ideas and experiences from the Pacific. Sydney, NSW: Commonwealth Study Conferences Australia.

Faleolo, M. M. (2009). Culturally valid social work education: A Samoan perspective. In C. Noble, M. Henrickson, \& I. Y. Han (Eds.), Social work education: Voices from the Asia Pacific (pp. 149-172). Carlton North, Victoria: The Vulgar Press.
Faleolo, M. M. (2013). Authentication in social work education: The balancing act. In C. Noble, M. Hendrickson, \& I. Y. Han (Eds.), Social work education: Voices from the Asia Pacific (2nd ed., pp.105-131). Sydney, NSW: University of Sydney Press.

Farrelly, T., \& Nabobo-Baba, U. (2014). Talanoa as empathic apprenticeship. Asia Pacific Viewpoint, 55(3), 319-330. https://doi.org/10.1111/apv.12060

Kemp, S. P., Marcenko, M. O., Lyons, S. J., \& Kruzich, J. M. (2014). Strength-based practice and parental engagement in child welfare services: An empirical examination. Children and Youth Services Review, 47(P1), 27-35. https://doi.org/10.1016/j.childyouth.2013.11.001

Kincheloe, J. L., \& Steinberg, \& Shirley, R. (2008). Indigenous knowledges in education: Complexities, dangers, and profound benefits. In N. K. Denzin, Y. S. Lincoln, \& L. Tuhiwai Smith (Eds.), Handbook of critical and indigenous methodologies (1st ed., pp. 135-156). Thousand Oaks, CA: Sage.

Lauta-Mulitalo, P. T. (1998). The role of Fa'asamoa in Social Work in New Zealand. Palmerston North, NZ: Massey University.

Magnus, P. (2009). Preparation for social work students to do cross-cultural clinical practice. International Social Work, 52(3), 375-385. http://doi. org/10.1177/0020872808102070

Mafileo, T., \& Vakalahi, H. F. O. (2016). Indigenous social work across borders: Expanding social work in the South Pacific. International Social Work. https://doi. org/10.1177/0020872816641750

Marlowe, J. M., Appleton, C., Chinnery, S.-A., \& Van Stratum, S. (2014). The integration of personal and professional selves: Developing students' critical awareness in social work practice. Social Work Education, 34(1), 60-73. http://doi.org/10.1080/02615479.2014.949230

Mathiesen, S. G., \& Lager, P. (2007). A model for developing international student exchanges. Social Work Education, 26(3), 280-291. http://doi. org/10.1080/02615470601049867

Nuttman-Shwartz, O., \& Berger, R. (2012). Field education in international social work: Where we are and where we should go. International Social Work, 55(2), 225-243. http://doi.org/10.1177/0020872811414597

Parker, J., \& Ashencaen Crabtree, S., Azman, A., Carlo, D. P., \& Cutler, C. (2015). Problematising international placements as a site of intercultural learning European Journal of Social Work, 18(3), 383-396. http://doi.org/10. 1080/13691457.2014.925849

Payne, M. (2014a). Strengths, narrative and solution practice. In Modern social work theory (pp. 243-270). Basingstoke: Palgrave Macmillan

Payne, M. (2014b). System and ecological practice. In Modern social work theory (Fourth, pp. 184-211). Basingstoke: Palgrave Macmillan.

Pettys, G. L., Panos, P. T., Cox, S. E., \& Oosthuysen, K. (2005). Four models of international field placement. International Social Work, 48(3), 277-288. https://doi. org/10.1177/0020872805051705

Pulotu-Endemann, F. K. (2001). Fonofale model of health. Pacific Models for Health Promotion. Retrieved from http://www.hauora.co.nz/resources/ Fonofalemodelexplanation.pdf 
Ravulo, J. (2016). Pacific epistemologies in professional social work practice, policy and research. Asia Pacific Journal of Social Work and Development, 26(4), 191-202. doi.org/10.1080/02185385.2016.1234970

Ravuvu, A. (1983). Vaka i Taukei - The Fijian way of life. Suva, Fiji: The University of the South Pacific.

Tamasese, K. (2002). Honouring Samoan ways and understandings: Towards culturally appropriate mental health services. International Journal of Narrative Therapy \& Community Work, 2, 64-71. Retrieved from http://search.informit.com.au/documentSummary;dn=126 407058629649;res=IELHSS

Tamasese, K., Peteru, C., Waldegrave, C., \& Busch, A. (2005). Ole Taeao Afua, the new morning: A qualitative investigation into Samoan perspectives on mental health and culturally appropriate services. Australian and New Zealand Journal of Psychiatry, 39, 300-309. http://doi. org/10.1111/j.1440-1614.2005.01572.x

Tuafuti, P. (2011). Multiple challenges in research within the Fa'asamoa context. Pacific-Asian Education, 23(2), 33-42.

Vaioleti, T. M. (2006). Talanoa research methodology: A developing position on Pacific research. Waikato Journal of Education 12(1), 21-34.

Vaka, S., Brannelly, T., \& Huntington, A. (2016). Getting to the heart of the story: Using talanoa to explore Pacific mental health. Issues in Mental Health Nursing, 37(8), 537-544. https://doi.org/10.1080/01612840.2016.1186253

Wehbi, S. (2009). Deconstructing motivations: Challenging international social work placements International Social Work, 52(1), 48-59. http://doi. org/10.1177/0020872808097750

Wong, Y., \& Pearson, V. (2007). Mission possible: Building social work professional identity through fieldwork placements in China. Social Work Education, 26(3), 292-310. http://doi.org/10.1080/02615470601049883

Yeom, H. S., \& Bae, H. O. (2010). Potential issues in field practicum student exchange between Korea and the USA. International Social Work, 53(3), 311-326. http:// doi.org/10.1177/0020872809359748

\section{ACKNOWLEDGMENTS}

Many thanks to the students of the Pacific Islands Field Education (PIFE) initiative who participated in the research, Prof Kevin Dunn, Prof Brian Stout, and Kate Saxton from the School of Social Sciences and Psychology of Western Sydney University, Dr Donald (Bruce) Yeates from the Faculty of Arts, Law and Education at the University of the South Pacific, and the invaluable research and writing assistance provided by Shannon Said. 